\title{
DA TEORIA DA REGULAÇÃO AO DIÁLOGO ENTRE AS FONTES DO DIREITO: CONTRIBUTOS A PARTIR DA OBRA DE ALAIN SUPIOT
}

\author{
FROM REGULATION THEORY TO DIALOGUE BETWEEN THE SOURCES OF LAW: \\ CONTRIBUTIONS FROM THE WORK OF ALAIN SUPIOT
}

\author{
Maria Cândida Simon Azevedo* \\ Wilson Engelmann **
}

\begin{abstract}
RESUMO: O presente estudo visa analisar como o Direito do Trabalho pode enfrentar a complexidade gerada pela sociedade atual. Para tanto, busca-se propor um panorama acerca da visão do Direito do Trabalho na concepção de Alain Supiot, na medida em que o autor procura em seus pilares de sustentação o fundamento desse ramo específico. Primeiramente, no segundo capítulo será analisada a crítica à atual conjectura do Direito do Trabalho na concepção de Supiot, na medida em que o desvirtuamento dos institutos ocasionou a desestruturação do ramo em questão. O terceiro capítulo tratará da reconstrução do Direito do Trabalho através da superação dos pressupostos positivistas tradicionais, trazendo à tona a teoria da regulação de Supiot, a qual visa, através do direito coletivo, propor uma reestruturação do Direito do Trabalho. Por fim, na medida em que a estrutura jurídica atual, proposta por Pontes de Miranda, não condiz com as necessidades impostas por essa inovação, há uma urgente necessidade em se rever a Teoria do Fato Jurídico, pois esta tem a lei como único suporte fático. Portanto, no último capítulo será proposto um diálogo entre as fontes do direito como a estrutura normativa para executar a teoria da regulação, na busca por respostas jurídicas apropriadas aos novos direitos e deveres, ou seja, o Estado deve fixar parâmetros e princípios, através dos quais os atores envolvidos diretamente terão que se basear e a partir daí buscar regulações próprias e adequadas.
\end{abstract}

PALAVRAS-CHAVE: Direito do Trabalho. Diálogo entre as Fontes. Teoria da Regulação.
ABSTRACT: This study aims to examine how labor law can face the complexity gerated by the present society. Therefore, it seeks to propose an overview about the labor law as it was designed by Alain Supiot, who sought the foundation of this particular legal branch in its supporting pillars. First, in the second chapter, the Supiot' critic to the current conjecture of labor law will be considered, since the distortion of institutes led to the disintegration of the legal branch in question. The third chapter will deal with the reconstruction of the Labor Law by overcoming the traditional positivist assumptions, bringing up the regulation theory of Supiot, which aims a reconstruction of the Labor Law through collective rights. Finally, since the current legal framework proposed by Pontes de Miranda in Brazilian Law isn't consistent with the requirements imposed by this innovation, there is an urgent need to review this theory, as it proposes the legislation as the unique support. Therefore, in the last chapter, a dialogue between the sources of Law as the regulatory framework to implement the regulation theory will be proposed, in the search for appropriate legal answers to the new rights and duties, understanding that the State should set parameters and principles that should be observed by the actors directly involved and search for the proper and adequate regulation.

SUMÁRIO: Introdução. Introdução. 1 O Direito do Trabalho na Concepção de Alain Supiot. 2 A Reconstrução do Direito do Trabalho: Superação dos Pressupostos Tradicionais. 3 O Diálogo entre as Fontes do Direito como a Estrutura Normativa para Executar a Teoria da Regulação. Considerações Finais. Referências.

\footnotetext{
"Especialista em Direito e Processo do Trabalho pela Universidade do Vale do Rio dos Sinos (UNISINOS), Rio Grande do Sul. Advogada.

*** Doutor e Mestre em Direito Público pelo Programa de Pós-Graduação em Direito da Universidade do Vale do Rio dos Sinos (UNISINOS), Rio Grande do Sul. Professor do Programa de Pós-Graduação em Direito da Universidade do Vale do Rio dos Sinos (UNISINOS). Coordenador Executivo do Mestrado Profissional em Direito da Empresa e dos Negócios da Universidade do Vale do Rio dos Sinos (UNISINOS). Líder do Grupo de Pesquisa JUSNANO, registrado no Conselho Nacional de Desenvolvimento Científico e Tecnológico (CNPq). Bolsista de Produtividade em Pesquisa do Conselho Nacional de Desenvolvimento Científico e Tecnológico $(\mathrm{CNPq})$.
} 


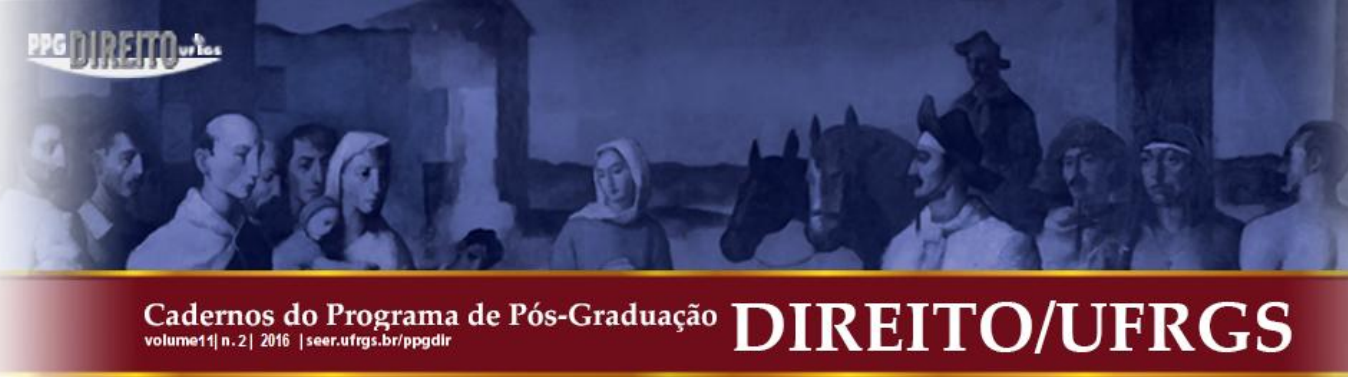

\section{INTRODUÇÃO}

A partir da concepção de que o Direito do Trabalho se encontra em uma crise, na medida em que seus pilares de sustentação encontram-se fragilizados ou, até mesmo, desvirtuados, é necessário operar uma quebra de paradigma em sua estrutura fundamental.

A visão do trabalhador como sujeito de direito, decorrente das reivindicações perpetradas com o passar dos anos, propiciou o surgimento do direito coletivo. Este, portanto, é a chave para o equilíbrio entre a regulamentação estatal e a flexibilização/desregulamentação que vem tomando força desde meados dos anos de 1970 . Nesse sentido, Alain Supiot faz uma análise crítica acerca da atual conjectura em que se encontra esse ramo específico, pois em seu fim último, acaba por servir à lei do mercado, à lei do lucro, ainda que as lutas para se alcançar um patamar mínimo de garantias tenham sido longas e desgastantes, em especial para a classe operária.

Portanto, surge a pergunta: como a lei pode se adaptar às mudanças da complexa sociedade em que vivemos tão rapidamente quanto necessário? Supiot reconhece a importância do direito coletivo, pois esse tem o condão de regular aquilo que o Estado/lei não alcança. Através disso, pode-se buscar outras formas de regulação sem a necessidade de intervenção do Poder Legislativo para tanto. Ou seja, as bases regulatórias poderão/deverão ser buscadas a partir da capacidade dos próprios atores envolvidos de regularem a si mesmos, no caso do Direito do Trabalho, através dos sindicatos de cada categoria profissional.

Primeiramente, abordar-se-á o Direito do Trabalho na concepção de Alain Supiot, demonstrando a crise de paradigma em que se encontra o Direito do Trabalho, em especial no que toca aos movimentos de flexibilização ou desregulamentação das leis trabalhistas. Em seguida será analisada uma reconstrução do Direito do Trabalho a partir da proposta de uma superação dos pressupostos positivistas tradicionais, através da teoria da regulação de Alain Supiot. E, por fim, será abordado o diálogo entre as fontes do Direito, como a estrutura normativa para executar a teoria da regulação, na medida em que o sistema do direito não mais pode permitir que normas sejam interpretadas ou aplicadas de forma separada do ordenamento jurídico como um todo. Deve sempre haver uma construção analítica do ordenamento, tendo como pilar a Constituição Federal. 


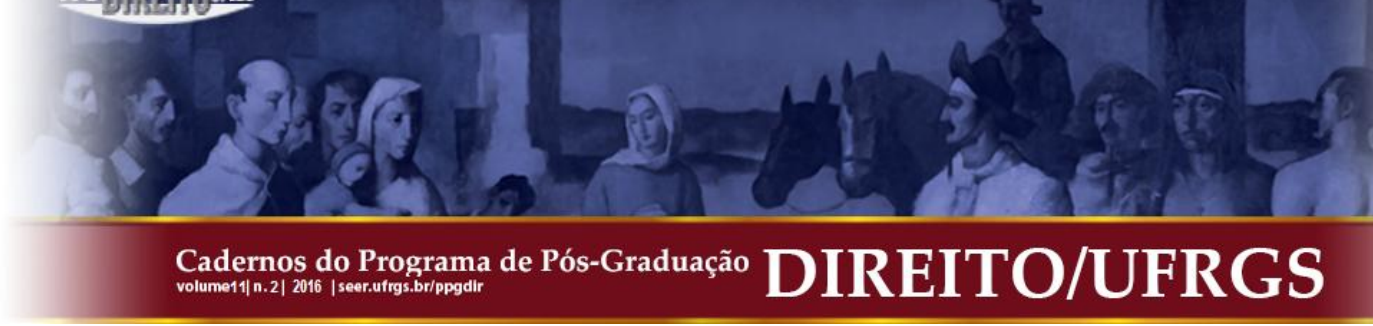

\section{O DIREITO DO TRABALHO NA CONCEPÇÃO DE ALAIN SUPIOT}

Alain Supiot, em sua obra Critique du Detroit du Travail, faz um apanhado histórico e critico acerca da atual conjectura do Direito do Trabalho, buscando chegar aos princípios que sustentam seus pilares. Supiot analisa profundamente as origens históricas - romana e germânica - do Direito do Trabalho, as quais se transformaram em uma operação compatibilizada "[...] (trabalho como bem e objeto do direito - relacionada à vertente contratual/romana; e trabalhador como pessoa e sujeito de direito - atrelada à vertente germânica)"

Nesse sentido, Supiot observa que a partir da visão do trabalhador como sujeito de direito, propicia o surgimento de regras mais protetivas. Entretanto, essa mesma regulamentação protetiva por parte do Estado pode, ao bel prazer do mercado, transformar-se em flexibilização e desregulamentação dos direitos anteriormente adquiridos. Esse é o quadro a que se está sujeito desde meados dos anos 1970, com a ocorrência da flexibilização/desregulamentação das leis trabalhistas. É evidente que essa flexibilização ou desregulamentação, ao contrário do que muitos autores sustentam, não gera mais empregos, mas tão somente beneficia determinados setores em desfavor dos trabalhadores.

Supiot cita como exemplo o Contrato do Primeiro Emprego imposto pelo governo francês em 2006, que, com o intuito de acabar com o desemprego de jovens, permitiu que as empresas/empregadores demitissem os jovens empregados de até 26 anos, até o segundo ano de contrato, sem qualquer explicação. ${ }^{2}$ Entretanto, essa desregulamentação, de forma inversa, acabou por aumentar o desemprego, pois oportunizava a demissão por aqueles empregadores que já pretendiam demitir, bem como dificultava a obtenção de emprego para aqueles maiores

\footnotetext{
${ }^{1}$ PORTILHO, Raphaela Magnino Rosa. O direito do trabalho na visão crítica de Alain Supiot. In: MISALIDIS, Mirta Gladys Lerena Manzo de; SILVA, Lucas Gonçalves da; BARBATO, Maria Rosaria (Orgs.). (Re)Pensando $o$ Direito: Desafios para a construção de novos paradigmas. 1. ed. Florianópolis: CONPEDI, 2014. Disponível em: <http://webcache.googleusercontent.com/search?q=cache:1XLojK2qTEJ:www.publicadireito.com.br/artigos/\%3Fcod\%3D092cb9ab3aaf99bd+\&cd=1\&hl=ptBR\&ct=clnk\&gl= br>. Acesso em: 22 abr. 2016.

${ }^{2}$ No direito francês, ao contrário do direito brasileiro (em que pese a Constituição Federal de 1988 preveja a motivação da despedida, até hoje não foi feita a lei complementar exigida para regulamentar tal previsão), há necessidade de motivação da despedida do empregado. Vide FRANÇA. Código de Trabalho. Disponível em: <https://www.legifrance.gouv.fr/affichCodeArticle.do;jsessionid=6FB218439340AB89D11EF619941A7270.tpd ila19v_3?idArticle=LEGIARTI000019071126\&cidTexte=LEGITEXT000006072050\&dateTexte=20160709>. Acesso em 09 jul. 2016.
} 


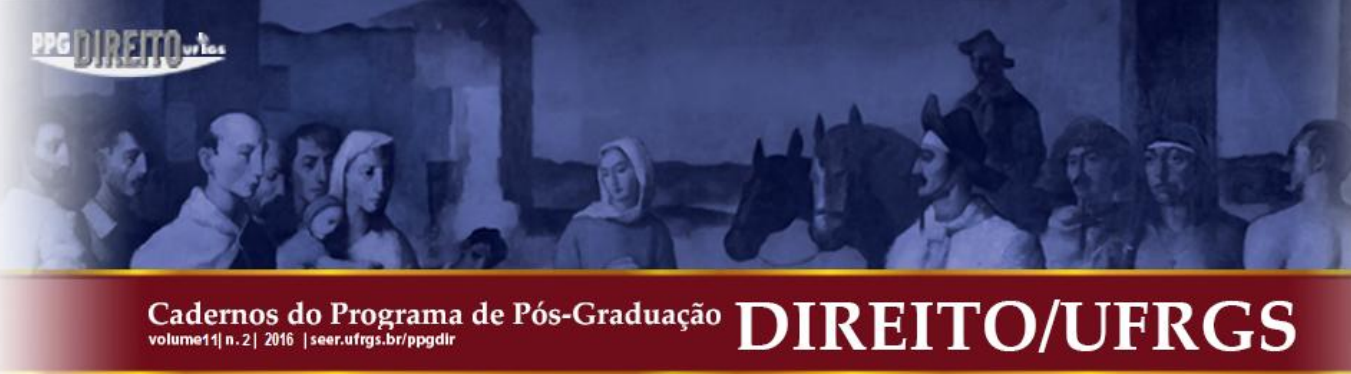

de 26 anos. Ou seja, de fato, não resolveu o problema do desemprego juvenil, pois proporcionou uma elevada rotatividade e um maior índice de demissões. ${ }^{3}$

Nesse sentido, é evidente que o Estado possui prioridades as quais mudam com o passar dos anos e com as trocas de poder, sempre havendo o privilégio de uma classe sobre outras. Nem sempre as regras serão as mesmas, se alternando de acordo com o as prioridades de quem está no poder. A sociedade é tão complexa que para regulamentá-la completamente seria necessário prever tudo, regulamentar tudo, o que, de fato, é impossível. Querer regulamentar tudo levaria a uma confusão de normas que as tornariam indecifráveis e impossíveis de serem respeitadas. ${ }^{4}$

Portanto, surge a pergunta: como a lei pode se adaptar às mudanças da complexa sociedade em que vivemos tão rapidamente quanto necessário? Ocorre que "O modelo de trabalho assalariado que dominou a era industrial - no qual um trabalhador renuncia a um grau de liberdade em troca de determinada proporção de segurança - já não pode ser aplicada na atualidade de maneira genérica"5.

Fala-se hoje (2016), no Brasil, com mais enfoque do que nos anos anteriores, em uma reforma trabalhista, quando, na realidade, a grande maioria dos dispositivos da Consolidação das Leis do Trabalho (CLT) já foram alterados, substituídos ou revogados. Supiot refere que, por exemplo, "As reformas do mercado de trabalho impostas na maioria dos países europeus têm se mantido circunscritas ao velho modelo e limitadas a piorar as condições para aqueles que se encontram nas classes mais pobres"6. Além disso, Supiot conclui que essas políticas vêm da falsa suposição de que a legislação trabalhista é um entrave à lucratividade e à livre concorrência, constituindo-se tão somente uma reformulação do mesmo modelo limitado a degradar cada vez mais as classes menos favorecidas. ${ }^{7}$

\footnotetext{
${ }^{3}$ Segundo Supiot, essa lei foi "Idealizado por um grupo de assessores econômicos do Primeiro Ministro, sem nem sequer consultar aos juristas do Ministério do Emprego, aprovado como uma 'questão de urgência', sem nenhuma negociação com os sindicatos e sem um debate parlamentar de fato, a medida exibia praticamente todos os defeitos que têm arruinado a reforma do direito trabalhista francês durante o último quarto de século". SUPIOT, Alain. Lei e trabalho. Um mercado mundial de regras? Tradução de Rinaldo José Varussa. Tempos Históricos. v. 17, $1^{\text {o }}$ semestre de 2013, p. 159. Disponível em: <http://e-revista.unioeste.br/index.php/ temposhistoricos/article/view/9013/6604>. Acesso em 03 mai. 2016.

${ }^{4}$ SUPIOT, Alain. Crítica del derecho del trabajo. Traducción de José Luis Gil y Gil. España: Ministerio de Trabajo y Assuntos Sociales, 1996.

${ }^{5}$ SUPIOT, Alain. op. cit., 2013, p. 157.

${ }^{6}$ SUPIOT, Alain. op. cit., 2013, p. 157.

7 SUPIOT, Alain. op. cit., 2013, p. 157.
}

Cadernos do Programa de Pós-Graduação em Direito PPGDir./UFRgS | Edição Digital | Porto Alegre | Volume XI | Número 2 | 2016 | P. $293-313$ 


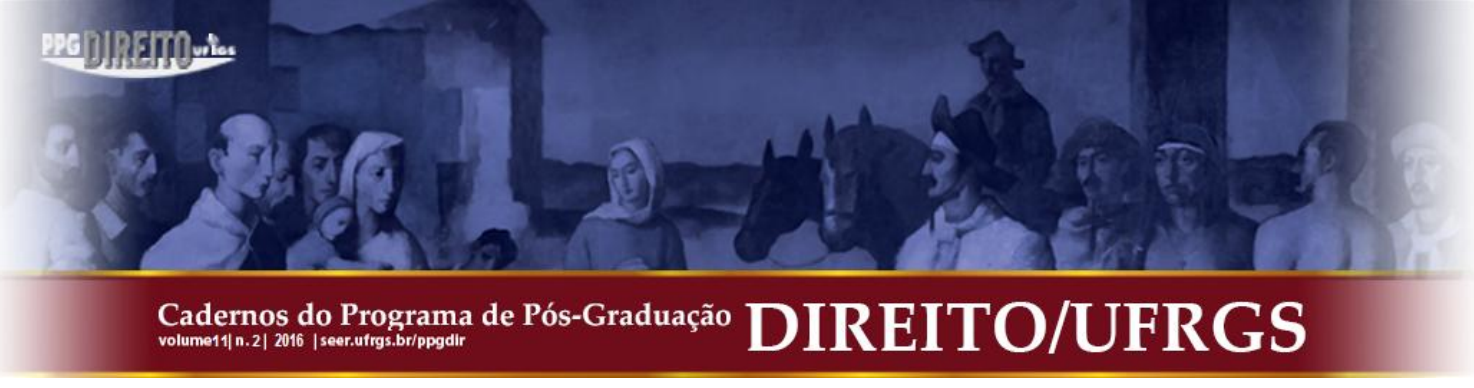

Alguns discursos tentam, assim, convencer de que garantias de jornadas íntegras, salários compatíveis e proteções aos trabalhadores em geral acabam por diminuir a oferta de emprego. De acordo com o viés a que se encontra afivelada a sociedade em determinada época, pode acarretar o desmantelamento de garantias trabalhistas, bem como a oneração da Seguridade Social. ${ }^{8}$ Portanto, “A lição tirada das duas guerras mundiais, que «a paz universal e duradoura só pode ser estabelecida com base na justiça social» é esquecida e o abandono de qualquer objetivo de justiça social a nível internacional é acompanhado sem surpresa da desigualdade em espiral [...]"(tradução nossa) ${ }^{9}$.

Não é de hoje que a prática de fazer acordo com o empregado para este sacar o Fundo de Garantia por Tempo de Serviço (FGTS) e receber o Seguro Desemprego (SD) é prática corriqueira no Brasil. Tal fato mostra-se extremamente oneroso ao Estado, na medida em que muitas vezes sequer há a efetiva demissão do empregado, que passa a trabalhar sem a Carteira de Trabalho assinada. Isso ocorre, também, em razão dos salários irrisórios aos quais estão submetidos muitos trabalhadores.

Nesse sentido, importante citar a contribuição de Supiot, quando refere que:

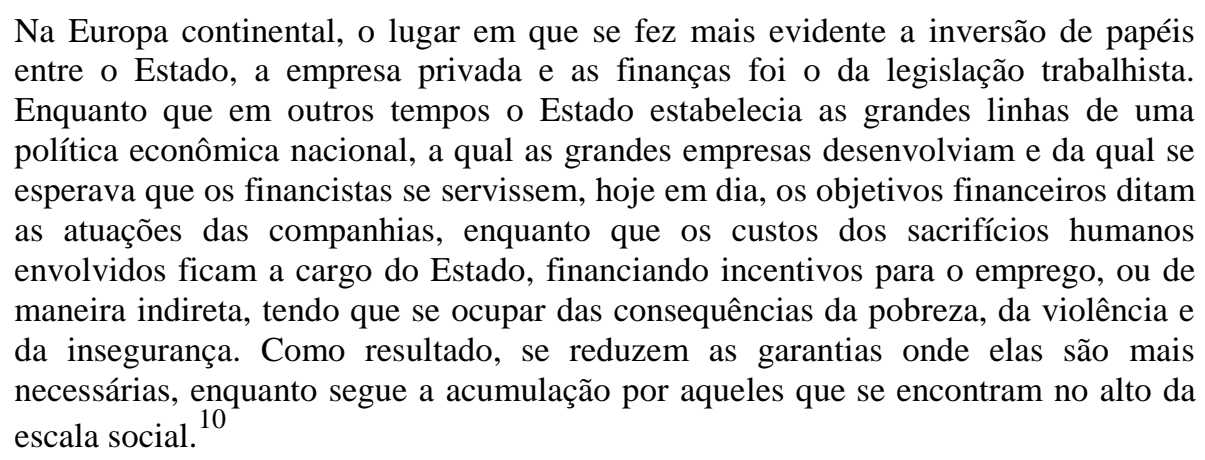

A crise de paradigma a qual se encontra o Direito do Trabalho na atualidade não é apenas mérito brasileiro, mas também de outros países. Crise, pois em seu fim último acaba por servir à lei do mercado, à lei do lucro, ainda que as lutas para alcançarmos um patamar mínimo de garantias tenham sido longas e desgastantes, em especial para a classe operária. Nesse sentido,

\footnotetext{
8 SUPIOT, Alain. op. cit., 2013, p. 157.

${ }^{9}$ SUPIOT, Alain. Face à l'insoutenable: les ressources du droit de la responsabilité (Indroduction). In : SUPIOT, Alain; DELMAS-MARTY, Mireille (Orgs.). Prendre la responsabilité au sérieux. 1. ed. Paris: Dépôt legal, 2015, p. 13.

${ }^{10}$ SUPIOT, Alain. op. cit., 2013, p. 157. 


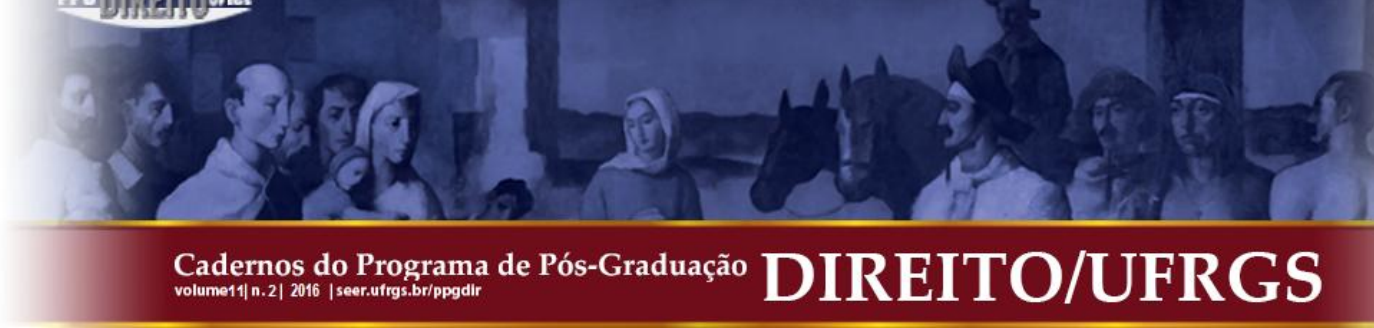

[...] a empresa não é o paradigma comunitário sobre o qual se fundamenta a dimensão coletiva das relações de trabalho, mas um lugar em que o jogo da subordinação faz quebrar os princípios de liberdade e de igualdade do direito civil e em que convém forçar o respeito a esses princípios em um plano coletivo. (tradução nossa) ${ }^{11}$.

Fazer com que os institutos já existentes cumpram cada qual seu devido papel, é fundamental. ${ }^{12}$ Essa é a proposta de Supiot, na medida em que reconhece a importância do direito coletivo na prática do Direito do Trabalho. ${ }^{13}$ Portanto, o Direito do Trabalho, sendo um direito diferenciado, deve operar de acordo com uma ruptura com os pressupostos tradicionais, a fim de se libertar das amarras do paradigma tradicional do Direito, que, em verdade, mais aprisiona do que protege.

\section{A RECONSTRUÇÃO DO DIREITO DO TRABALHO: SUPERAÇÃO DOS PRESSUPOSTOS TRADICIONAIS}

Consoante pode-se observar do capítulo anterior, é preciso haver uma redefinição do direito do trabalho, uma ruptura dos pressupostos tradicionais. Nesse sentido, Supiot defende o que ele chama de teoria da regulação (o que equivale à regulação não tradicional), pois acredita que a chave para o equilíbrio é a esfera coletiva proporcionada pelo direito do trabalho (um trabalhador sozinho não tem a mesma força que um coletivo de trabalhadores).

Assim, é possível distinguir dois tipos de regulação, a regulação tradicional (Estatal) através de leis -, e a regulação não tradicional, às quais Supiot chama, respectivamente, de regulamentação - regras do exterior - e regulação - regras internas (homeostasia). Supiot refere que a regulação legal não tem o condão de estabelecer parâmetros ou regular a

\footnotetext{
${ }^{11}$ SUPIOT, Alain. op. cit., 1996, p. 174.

12 O papel fundamental do Direito do Trabalho é, portanto, “[...] o de «civilizar» as relações sociais, quer dizer, substituir as relações de poder por relações de direito e assegurar a todos o estado de sujeitos de direito livres e iguais. Entretanto, enquanto que o direito civil de obrigações evoluciona sobre um terreno sólido - o do sujeito de direito, dono de seu corpo e de sua vontade - a subordinação priva o trabalhador de sua liberdade e o situa em uma relação juridicamente desigual com o empresário. Faz desaparecer o trabalhador, enquanto sujeito de direito, do horizonte do direito civil quando entra na empresa, para deixar espaço a um simples sujeito, submetido ao poder de direção do empresário. O direito do trabalho vem tendo e tem por primeira razão de ser a de aliviar esta carência, isto é, «civilizar» o poder empresarial, dando-lhe um marco jurídico onde é exercido, quer dizer, na empresa". (tradução nossa). SUPIOT, Alain. op. cit., 1996, p. 175.

${ }^{13}$ Mais especificamente, Alain Supiot refere que "Foi a invenção do coletivo e suas consequências - os direitos coletivos, as liberdades coletivas, a negociação coletiva e as convenções coletivas -, que tem permitido ultrapassar os impasses da submissão voluntária e definir um direito em que podem conviver a subordinação e a liberdade". (tradução nossa). SUPIOT, Alain. op. cit., 1996, p. 148.
} 
totalidade da complexa sociedade em que vivemos, muito menos acompanhar a constante mutação desta. $^{14}$

O modelo jurídico proposto por Pontes de Miranda (Teoria do Fato Jurídico) é considerado a estrutura fundamental da Ciência Jurídica atual, segundo a qual " [...] o mundo jurídico é formado pelos fatos jurídicos e estes, por sua vez, são o resultado da incidência da norma jurídica sobre o seu suporte fáctico quando concretizado no mundo dos fatos"15. Conforme Pontes de Miranda, “A regra jurídica é norma com que o homem, ao querer subordinar os fatos a certa ordem e a certa previsibilidade, procurou distribuir os bens da vida" ${ }^{\prime 6}$. De acordo com a lógica da estrutura pontesiana, esta está estruturada em três planos, nos quais os fatos da vida vão ocorrendo (plano da existência), preenchendo o suporte fático (plano da validade) e produzindo os efeitos previamente definidos na norma (plano da eficácia). Portanto, “[...] o fato jurídico é o que entra, do suporte fático, no mundo jurídico, mediante a incidência da regra jurídica sobre o suporte" ${ }^{17}$. Essa estrutura jurídica é fortemente influenciada pelo positivismo jurídico de Hans Kelsen, segundo o qual o Direito é conceituado como um conjunto de regras impostas pelo Estado a partir de critérios rigorosamente formais. ${ }^{18}$ Nessa lógica, o Direito tende a buscar fatos que ocorreram no passado para, assim, regulamentar o futuro, o que, notadamente, mostra-se insuficiente para suprir as necessidades que a sociedade atual impõe.

Portanto, está-se a fazer, também, uma crítica ao modelo de norma de Hans Kelsen, na medida em que este tem como fundamento buscar fatos que ocorreram no passado, para regulamentar o futuro. Tal modelo mostra-se totalmente insuficiente para suprir as necessidades e constantes mudanças que a sociedade atual está fundamentada. Isto é, por óbvio que "[...] a evolução das técnicas acarreta transformações do Direito: era preciso que nascesse a informática para que se preocupasse em legislar sobre a informática e as liberdades..."19. Mas essas transformações ocorrem de forma retardada, posterior ao

\footnotetext{
${ }^{14}$ SUPIOT, Alain. Homo juridicus: ensaio sobre a função antropológica do direito. Tradução de Maria Ermantina de Almeida Prado Galvão. São Paulo: WMF Martins Fontes, 2007.

${ }^{15}$ MELLO, Marcos Bernardes de. Teoria do fato jurídico: plano da existência. 20. ed. São Paulo: Saraiva, 2014, p. 52.

${ }^{16}$ PONTES DE MIRANDA, Francisco Cavalcanti. Tratado de Direito Privado. Tomo I. Rio de Janeiro: Borsoi, 1954, p. 03.

${ }^{17}$ PONTES DE MIRANDA, Francisco Cavalcanti. op. cit., p. 04.

${ }^{18}$ ENGELMANN, Wilson. Crítica ao positivismo jurídico: princípios, regras e o conceito de direito. Porto Alegre: Sérgio Antônio Fabris, 2001, p. 82.

${ }^{19}$ SUPIOT, Alain. op. cit., 2007, p. 139.
} 
surgimento da questão a que se regulamenta na sociedade. Primeiro deve ocorrer o fato na sociedade para que, posteriormente, o direito passe a regulamentá-lo.

As necessidades atuais da sociedade são diferentes, a imediatidade é medida que se impõe, em especial no que toca à saúde e segurança das pessoas (do trabalhador). Para Supiot, o grande desenvolvimento da sociedade contemporânea é o surgimento da negociação coletiva no direito do trabalho e a contratualização do direito civil. ${ }^{20}$ Entretanto, a individualização, ainda com muita força, acaba por enfraquecer a esfera coletiva. Além disso, a flexibilização toma força com a permissão legal de flexibilização dos direitos através da negociação coletiva. Na verdade, no Brasil, por exemplo, o desvirtuamento do direito coletivo acaba por transformá-lo em um mecanismo de flexibilização, prejudicando muitas vezes o seu papel fundamental, ou seja, o de assegurar as necessidades especiais de cada classe.

Conforme observado anteriormente, a subordinação aprisiona o trabalhador, que, de mãos amarradas, não pode medir forças com o empresário. A regulamentação estatal, proporcionada pelo Direito do Trabalho, portanto, surge como uma forma de libertação das amarras do trabalhador, visando equipará-lo ao empresário, de forma a protege-lo do que não consegue se proteger sozinho. Entretanto,

[...] uma reflexão faz-se necessária: não se pode perder de vista que Estado e Direito não se confundem entre si, ao contrário do que possa parecer. O Estado tem motivações políticas a partir da preponderância de certas classes. A classe que controla politicamente é aquela que vai definir qual o grau de proteção que o Estado irá conceder. Até que ponto essa estrutura pretensamente libertadora realmente liberta e não aprisiona mais ainda? (grifo nosso) ${ }^{21}$.

É nesse sentido que a dimensão coletiva é a chave para o equilíbrio, pois ao mesmo tempo que protege, o Estado pode permitir regras de flexibilização dessa proteção. Portanto, deve ocorrer uma ruptura com a estrutura do Direito, na qual o Estado deve regulamentar padrões gerais mínimos e inflexíveis e o direito coletivo regular as questões específicas. A regulamentação e a regulação se complementam, não se excluem (cooperação entre as esferas pública e privada).

Levada ao pé da letra, a ideia de regulação expressa um mundo totalmente ausente de conflitos sociais, que, no Direito, tomou forma através do chamado contratualismo, segundo o qual o ser humano não deve ser submetido a certos limites senão aqueles impostos por ele

\footnotetext{
${ }^{20}$ SUPIOT, Alain. op. cit., 2007, p. 159.

21 PORTILHO, Raphaela Magnino Rosa. op. cit.
} 


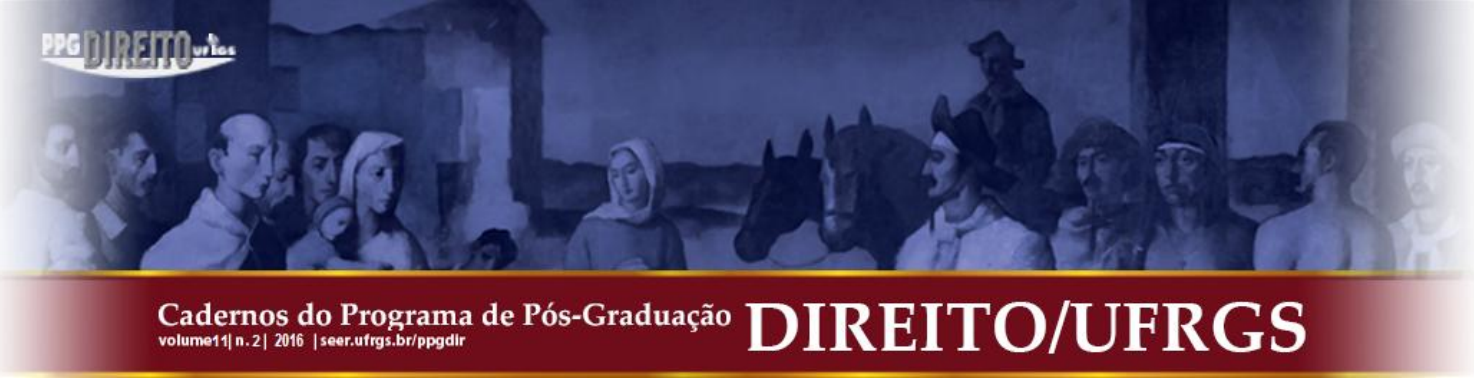

mesmo. ${ }^{22}$ Entretanto, "Nenhuma sociedade humana poderia evidentemente funcionar sobre uma base assim e temos, portanto, de lembrar que não há regulação sem regulador, seja na ordem da vida profissional ou na da vida privada"23.

Nesse sentido, interessante citar Mireille Delmas-Marty quando refere que "Ao vermos a profusão de normas que embaralham a nossa imagem da ordem jurídica, sentimos a necessidade de um direito comum, em todos os sentidos do termos" ${ }^{24}$. Delmas-Marty propõe o que ela chama de um Direito comum, ou seja, "Um direito acessível a todos, que não seria imposto de cima como verdade revelada, pertencente apenas aos intérpretes oficiais, mas consagrado de baixo como verdade compartilhada, portanto relativa e evolutiva [...]" ${ }^{, 25}$, mas um direito "[...] comum igualmente a diferentes setores do direito para assegurar a coerência de cada sistema, apesar da especialização crescente das regras [...]"26.

Então surge a questão: o que, na relação de trabalho, deve ser regulamentada pelo Direito (lei), e o que deve ser deixado para a regulação social, ou seja, outras formas de regulação? Para Supiot “[...] apenas uma regulação adequada, e não uma regulamentação rígida, pode proteger a sociedade da desordem entrópica [...]"27. Mas ambas (regulamentação e regulação) devem operar conjuntamente e de forma coordenada, na medida em que o Estado/lei deve fixar parâmetros mínimos (princípios e objetivos) e o direito coletivo aplica esses princípios e objetivos adaptando-os à realidade de cada particularidade.

\section{O DIÁlOGo ENTRE AS FONTES DO DIREITO COMO A ESTRUTURA NORMATIVA PARA EXECUTAR A TEORIA DA REGULAÇÃO}

A partir dessa reflexão proporcionada por Supiot, deve-se, então, objetivar a aplicação da teoria da regulação, através de um diálogo entre as fontes do direito. $\mathrm{O}$ diálogo das fontes se desenvolveu a partir da ideia de compatibilização de normas, segundo a qual o Direito deve, a partir de uma reestruturação de seus pressupostos tradicionais, buscar uma reorganização das fontes a fim de melhor se adequar à cada necessidade específica imposta

\footnotetext{
${ }^{22}$ SUPIOT, Alain. op. cit., 2007, p. 161.

${ }^{23}$ SUPIOT, Alain. op. cit., 2007, p. 161.

24 DELMAS-MARTY, Mireille. Por um direito comum. Tradução de Maria Ermantina de Almeida Prado Galvão. São Paulo: Martins Fontes, 2004, p. IX.

${ }^{25}$ DELMAS-MARTY, Mireille. op. cit., p. IX.

${ }^{26}$ DELMAS-MARTY, Mireille. op. cit., p. IX.

${ }^{27}$ SUPIOT, Alain. op. cit., 2007, p. 159.
} 


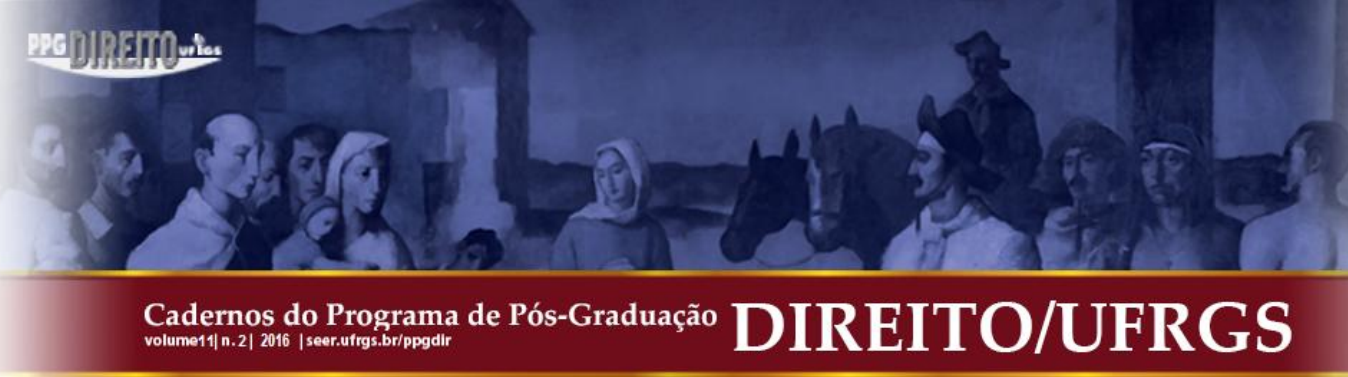

pela complexa sociedade atual. A teoria, primeiramente proposta por Erik Jayme, foi introduzida no Brasil por Claudia Lima Marques. ${ }^{28}$

Propõe-se, então, uma forma de buscar o suporte fático alvitrado por Pontes de Miranda em outras fontes que não sejam apenas a lei, ou seja, propõe-se um alargamento do suporte fático, visando identificar seus elementos no Direito e não somente na lei. ${ }^{29} \mathrm{~A}$ teoria do diálogo das fontes de Jayme pressupõe que o sistema jurídico haja com certa coerência sem contradição, sendo que na ocorrência de duas fontes contrastantes, deve-se buscar coordenálas num diálogo das fontes. ${ }^{30}$

No mesmo sentido do diálogo das fontes, Wilson Engelmann, propõe um diálogo entre as fontes do Direito, por entender ser mais abrangente. Assim, ao contrário (ou no mesmo sentido) do diálogo das fontes de Jayme, o diálogo entre as fontes do Direito é mais amplo, pois esse diálogo ainda tem como objetivo salvar uma das normas em conflito. Ou seja, “[...] propõe um efetivo diálogo, que não exige necessariamente apenas a interlocução de duas (di) fontes, mas uma efetiva reordenação das diversas fontes de onde emergem normas jurídicas" $" 31$.

A solução aqui é ordená-las de forma horizontal (uma ao lado da outra) e não mais verticalizada na forma de um modelo escalonado em pirâmide, proporcionando, assim, a abertura do ordenamento jurídico para uma pluralidade de fontes a fim de que estas incorporem o lugar da lei na caracterização do suporte fático, tendo a Constituição como principal filtro. ${ }^{32}$

\footnotetext{
28 "Diálogo das fontes, que, no direito brasileiro, significa a aplicação simultânea, coerente e coordenada das plúrimas fontes legislativas, leis especiais ( como o Código de Defesa do Consumidor e a lei de planos de saúde) e leis gerais ( como o Código Civil de 2002), de origem internacional (como a Convenção de Varsóvia e Montreal) e nacional ( como o Código Aeronáutico e as mudanças do Código de Defesa do Consumidor), que, como afirma o mestre Heidelberg, tem campos de aplicação convergentes, mas não mais totalmente coincidentes ou iguais". MARQUES, Claudia Lima. O "diálogo das fontes" como método da nova teoria geral do direito: um tributo a Erik Jayme. In: MARQUES, Claudia Lima (Coord.). Diálogo das fontes: do conflito à coordenação de normas do direito brasileiro. São Paulo: Revista dos Tribunais, 2012, p. 19-20.

${ }^{29}$ ENGELMANN, Wilson. A (re) leitura da teoria do fato jurídico à luz do "diálogo entre as fontes do direito": abrindo espaços no direito privado constitucionalizado para o ingresso de novos direitos provenientes das nanotecnologias. In: CALLEGARI, André Luís; STRECK, Lenio Luiz; ROCHA, Leonel Severo (Orgs.). Constituição, sistemas sociais e hermenêutica. Anuário do Programa de Pós-Graduação em Direito da UNISINOS: mestrado e doutorado. n. 7. Porto Alegre: Livraria do Advogado, 2010, p. 295.

30 JAYME, Erik. Direito internacional privado e cultura pós-moderna. Cadernos do programa de PósGraduação em Direito PPGDir./UFRGS. v. 1, n. 1, mar. 2003, p. 109. Disponível em: <http://seer.ufrgs.br/index.php/ppgdir/article/view/43487/27366>. Acesso em: 29 jun. 2016.

${ }^{31}$ ENGELMANN, Wilson. op. cit., 2010, p. 298.

${ }^{32}$ ENGELMANN, Wilson. op. cit., 2010, p. 296.
} 


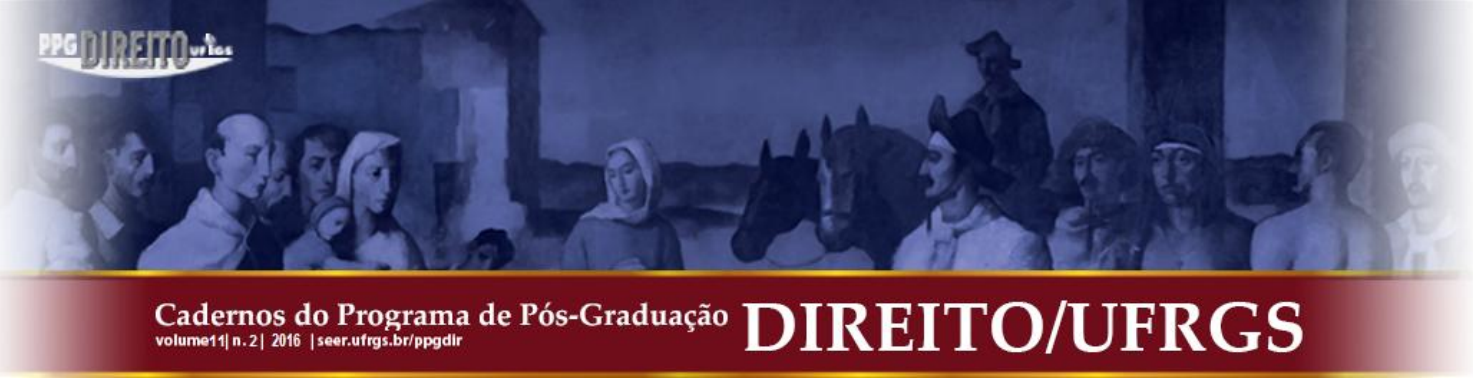

No tocante ao Direito do Trabalho, os princípios que norteiam seus pilares já proporcionam, há muito, um legítimo diálogo entre as fontes, ainda que de forma um pouco mais tímida. Mas, "Tradicionais autores do Direito do Trabalho brasileiro afirmam que, em se tratando de hierarquia de fontes trabalhistas, a pirâmide kelseniana (estrutura escalonada das normas) não é aplicável, pois sempre ocupará o vértice a norma mais favorável” ${ }^{, 36}$. Entretanto, há que se levar em consideração que, em muitas oportunidades, para escolher a norma mais favorável, é necessário se perguntar o que é mais favorável, pois sempre haverá um juízo de valor. $^{37}$

É, portanto, nesse sentido que Supiot defende o direito coletivo como a chave para o equilíbrio, desde que utilizado com fim único de cumprir sua função/valor. ${ }^{38}$ Pois, o desvirtuamento da função primordial do direito coletivo do trabalho tem trazido (e traz) o desequilíbrio desse ramo, na medida em que é utilizado como forma de flexibilização das leis trabalhistas, enquanto que seu papel é o de regular aquilo que o Estado/lei não tem condições de alcançar. A especificidade do direito coletivo do trabalho proporciona a regulação de matérias que seriam inalcançáveis ao legislador, na medida em que a complexidade da sociedade atual exige um alto nível de especialização em cada setor. ${ }^{39}$

Dessa forma, "A organização horizontal das fontes do Direito irá permitir um movimento de construção coletiva de respostas legais, destacando as contribuições do Direito (em lato senso) [...]"40 (tradução nossa), ou seja, a jurisprudência, os costumes, a doutrina, os contratos, as regulações de grupos sociais e, mais especificamente no Direito do Trabalho, as normas coletivas e outras alternativas e formas não Estatais de judicialização de fatos sociais

\footnotetext{
36 ARAÚJO, Francisco Rossal de; COIMBRA, Rodrigo. Direito do Trabalho - I. São Paulo: LTr, 2014, p.147.

37 ARAÚJO, Francisco Rossal de; COIMBRA, Rodrigo. op. cit., p.148.

38 "Este valor - e a consequente direção teleológica imprimida a este ramo jurídico especializado - consiste na melhoria das condições de pactuação da força de trabalho na ordem socioeconômica”. DELGADO, Maurício Godinho. Direito coletivo do trabalho. 4. ed. São Paulo: LTr, 2011, p. 23.

${ }^{39} \mathrm{Um}$ exemplo bastante urgente é a questão das nanotecnologias. Nanotecnologia é a denominação dada à alternativa de manipular a matéria em escala nanoscópica. Produtos contendo nanotecnologia são comercializados no mercado mundial e acabam sendo consumidos sem qualquer distinção. Há que se considerar que não estamos tratando de um produto comum, ou melhor, temos que ter a consciência de que produtos contendo material em escala nano podem ser prejudiciais tanto ao meio ambiente quanto à saúde humana. Não existe certeza das reações que determinados produtos podem ter quando em contato com o meio ambiente ou com o ser humano a curto e a longo prazo. A comercialização de diversos produtos e o manuseio destes materiais contendo nanotecnologia é uma das principais preocupações que o Direito deve ter, eis que dessa inovação decorre o desafio de regulamentar questões futuras, o que é um problema para a estrutura jurídica atual. ENGELMANN, Wilson. op. cit., 2013.

${ }^{40}$ ENGELMANN, Wilson. Nanotechnology, law and innovation. Deutschland: LAP LAMBERT Academic Publishing GmbH \& Co. KG, 2011, p. 74.
}

\section{4}




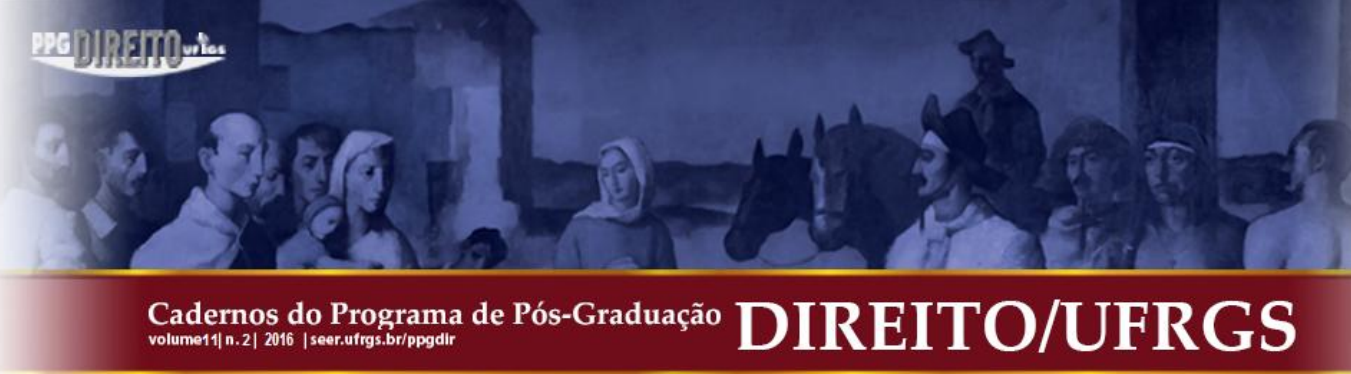

e resolução de conflitos, que deverão ser analisadas conjuntamente, a fim de que respostas jurídicas adequadas sejam alcançadas.

Supiot refere que a regulação legal não tem o condão de estabelecer parâmetros ou regular a totalidade da complexa sociedade em que vivemos, muito menos acompanhar a constante mutação desta. ${ }^{41}$ Portanto, "Regulamentar é ditar regras do exterior, ao passo que regular é fazer que se observem as regras necessárias ao funcionamento homeostático de uma organização" $^{\text {42 }}$. Ressalta-se que a noção de regulação foi trazida da biologia, segundo a qual homeostasia é a capacidade de "[...] conservar certo número de constantes internas apesar das variações do meio exterior [...]”,43. Há que termos em mente a possibilidade das organizações e os atores privados adaptarem-se sozinhos às novas necessidades e variações de seu meio ambiente, na medida em que a rigidez da regulamentação não consegue proteger adequadamente a sociedade. Ou seja, "Segundo a teoria cibernética, apenas uma regulação adequada, e não uma regulamentação rígida, pode proteger a sociedade da desordem entrópica $[\ldots]^{, 44}$.

Como bem salienta Supiot, "O ideal de uma sociedade capaz de regular a si mesma expressa-se, enfim, no grande desenvolvimento contemporâneo da negociação coletiva e, de modo mais geral, na contratualização das relações sociais" "45 . Nesse sentido, salienta-se a "[...] dignidade humana como direito que só pode ser transigido se for reconsiderada toda a ordem jurídica, e que transcende a velha oposição entre matéria e espírito, reconhecendo o corpo e suas necessidades físicas como elementos da dignidade a que não se pode renunciar"46. "Aí situa-se o ponto inicial de uma 'teoria da regulação', que engloba os homens, os animais e as máquinas e que deve conduzir num mesmo ritmo ao progresso das máquinas e ao do Direito" $" 47$.

"Essa crítica da rigidez da regulamentação e esse apelo a uma regulação que permita às organizações se adaptarem sozinhas às variações de seu meio ambiente [...]"48 decorre, além

\footnotetext{
${ }^{41}$ SUPIOT, Alain. op. cit., 2007.

${ }^{42}$ SUPIOT, Alain. op cit., 2007 , p. 159.

${ }^{43}$ SUPIOT, Alain. op. cit., 2007, p. 159.

${ }^{44}$ SUPIOT, Alain. op. cit., 2007, p. 159.

${ }^{45}$ SUPIOT, Alain. op. cit., 2007, p. 159.

${ }^{46}$ VENTURA, Deisy. O espírito de filadélfia - a justiça social diante do mercado total. Direito \& Práxis. v. 6, n. 12, 2015, p. 692. Disponível em: <http://www.e-publicacoes.uerj.br/index.php/ revistaceaju/article/view/19320/14054>. Acesso em: 14 jul. 2016.

${ }^{47}$ SUPIOT, Alain. op. cit., 2007, p. 155.

${ }^{48}$ SUPIOT, Alain. op. cit., 2007, p. 160.
} 
da cibernética e das novas tecnologias da informação e da comunicação, da ideia trazida pelo

Direito do Trabalho por sua ascensão em negociar coletivamente. ${ }^{49}$. Ou seja, "Com o recuo da heteronomia em proveito da auto-regulamentação profissional, deu-se uma nova distribuição dos papéis entre a lei, que fixa princípios e objetivos por atingir, e a negociação coletiva que concorre para a definição desses objetivos [...]" ${ }^{, 50}$, adaptando esses objetivos aos limites impostos pela lei e pelas necessidades particulares de cada coletividade.

Um exemplo disso é o acordado entre o Sindicato da Indústria de Produtos Farmacêuticos no Estado de São Paulo e o Sindicato dos Trabalhadores nas Indústrias Químicas, Farmacêuticas, Plásticas, de Explosivos, Abrasivos, Fertilizantes e Lubrificantes de Osasco e Cotia, também do Estado de São Paulo, pois incluíram em suas negociações coletivas a questão relativa ao manuseio, pelos trabalhadores, de produtos contendo nanotecnologia, que, no ano de 2012, resultou na seguinte cláusula:

\section{Saúde e Segurança do Trabalhador}

Condições de Ambiente de Trabalho

\section{CLÁUSULA OITAVA - NANOTECNOLOGIA}

A empresa garantirá que os membros da CIPA e do SESMT sejam informados quando da utilização de nanotecnologia no processo industrial. A CIPA, o SESMT e os trabalhadores terão ainda acesso a informações sobre riscos existentes à sua saúde e as medidas de proteção a adotar. ${ }^{51}$ (grifo do autor).

Dois anos depois, em decisão da Sessão Especializada em Dissídios Coletivos, o Tribunal Regional do Trabalho da Décima Quinta Região (Campinas/SP), ao julgar o dissídio coletivo de n. 0006151-86.2013.5.15.0000 (DC), no qual foi suscitante o Sindicato dos Trabalhadores nas Indústrias da Fabricação do Álcool, Etanol, Bietanol, Biocombustivel, Químicas e Farmacêuticas de Ribeirão Preto e Região e suscitada a empresa LDC SERV BIOSEV BIOENERGIA S.A., proferiu a seguinte decisão acerca do uso das nanotecnologias pela empresa suscitada:

[...] CLÁUSULA 84 ${ }^{\mathrm{a}}$ - NANOTECNOLOGIA As empresas são obrigadas a informar a entidade sindical sobre o uso de nanotecnologia no processo industrial e

\footnotetext{
${ }^{49}$ SUPIOT, Alain. op. cit., 2007, p. 160.

${ }^{50}$ SUPIOT, Alain. op. cit., 2007, p. 160.

51 SINDICATO DA INDÚSTRIA DE PRODUTOS FARMACEUTICOS NO ESTADO DE SÃO PAULO (SINDUSFARMA); SINDICATO DOS TRABALHADORES NAS INDÚSTRIAS QUÍMICAS, FARMACÊUTICAS, PLÁSTICAS, DE EXPLOSIVOS, ABRASIVOS, FERITILIZANTES E LUBRIFICANTES DE OSASCO E COTIA. Termo aditivo a convenção coletiva de trabalho. São Paulo, 19 abr. 2012. Disponível em: <http://webcache.googleusercontent.com/search?q=cache:h7RyKDTb920J: www.sindusfarma.org.br/informativos/Aditivo_Osasco2012_2013.pdf+\&cd=1\&hl=pt-BR\&ct=clnk\&gl=r>.
}

Acesso: 29 jun. 2016. 


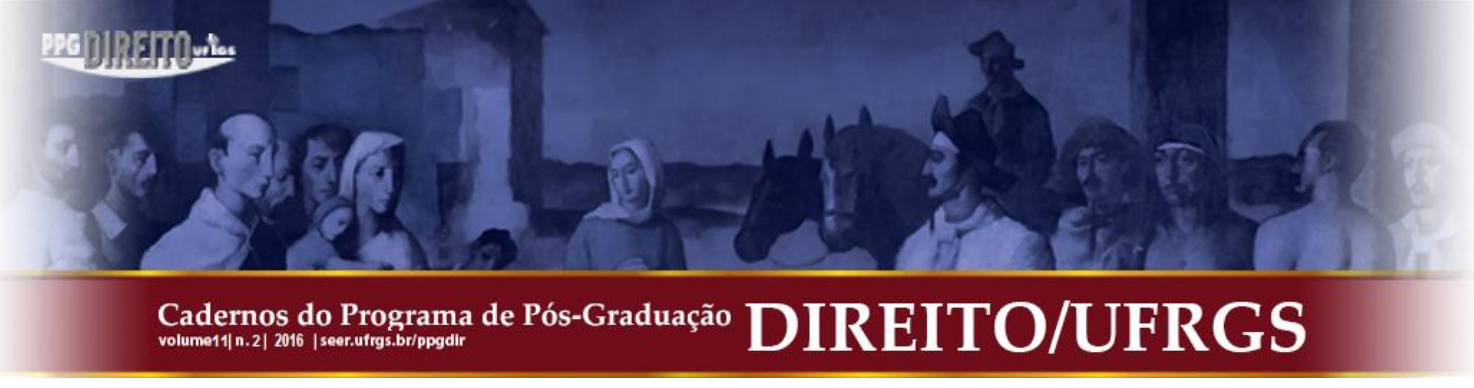

eficácia depende da qualidade das comunicações [...]"54 entre as partes envolvidas. É nesse sentido que os trabalhadores devem unir esforços para atingir os objetivos pretendidos, contra a classe opressora, que, em verdade, dita as leis do mercado e consegue desvirtuar o ordenamento aos seus próprios objetivos. Portanto, o direito coletivo deve buscar aprimorar cada vez mais suas funções, a fim de coordenar o que é importante e o que não o é, dentro de cada categoria específica de trabalhadores, pois somente através de sua especificidade é possível o trabalhador estar fortemente e devidamente protegido.

\section{CONSIDERAÇÕES FINAIS}

Os movimentos de flexibilização/desregulamentação vêm tomando força com o passar dos anos, impondo reformas que buscam oprimir a classe trabalhadora e beneficiar àqueles que estão no poder. Esse é o quadro no qual nos encontramos desde meados dos anos de 1970. Nesse sentido, busca-se, através de uma ponderação crítica, analisar as contribuições propostas por Alain Supiot acerca das raízes histórias do ramo do Direito do Trabalho, o qual visa alcançar seus pilares de sustentação.

A partir da visão do trabalhador como sujeito de direito e do consequente surgimento do direito coletivo, possibilitou à essa classe lutar por seus direitos, visando o benefício do coletivo e não mais de forma apenas individual. Entretanto, pode-se observar que, não especialmente o Direito do Trabalho, mas o ramo do Direito em si, encontra-se em uma crise de paradigma, na medida em que visa beneficiar uma classe em detrimento de outra, como o que vem ocorrendo com a classe trabalhadora.

É em razão disso que Supiot propõe uma teoria da regulação, pois defende que o direito coletivo é a chave para o reequilíbrio do Direito do Trabalho, tendo em vista que a tradicional forma de regulamentação não pode mais dar conta da complexidade da sociedade atual, ou seja, não tem o condão de estabelecer parâmetros ou regular a totalidade da complexa sociedade em que vivemos, muito menos acompanhar a constante mutação desta.

Além disso, está adstrita à lei como único meio de regulamentação, fato que, como bem ressaltado no decorrer do trabalho, deixa o grau de proteção nas mãos da classe controladora ou das motivações políticas do governo. Assim, nota-se que este meio regulador da sociedade

\footnotetext{
54 SUPIOT, Alain. op. cit., 2007, p. 163.
}

Cadernos do Programa de Pós-Graduação em Direito PPGDir./UFRGS | Edição Digital | Porto Alegre | Volume XI | Número 2 | 2016 | P. $293-313$ 


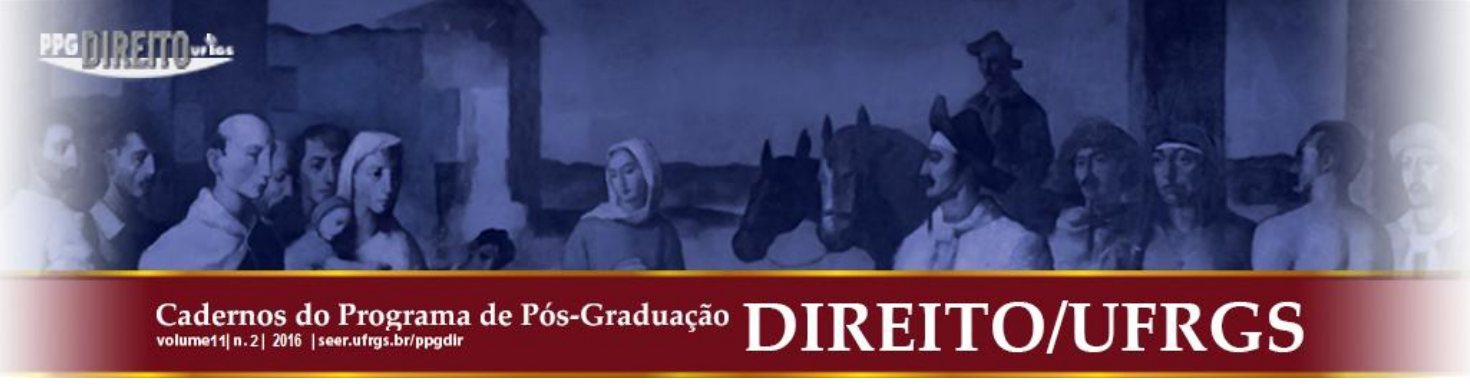

está fortemente influenciado pelo tipo de governo que está no poder, ensejando que aquela mesma lei que protege pode se transformar em um meio de flexibilizar ou desregulamentar os direitos anteriormente concedidos.

Em sendo assim, a partir do diálogo entre as fontes do direito, pode-se buscar a estrutura normativa para executar a teoria da regulação proposta por Alain Supiot, pois este defende que somente uma regulação adequada e não uma regulamentação rígida pode efetivamente proteger a sociedade e fazer o Direito cumprir seu papel. Assim, deve-se operar uma reestruturação das normas, que não mais serão analisadas de forma escalonada, mas sim verticalmente, sob a forma de cooperação mútua.

A partir daí o Direito do Trabalho deve se reestruturar e buscar rever sua função e seus princípios basilares, a fim de efetivamente proteger a classe trabalhadora, buscando resguardo no direito coletivo, a fim de que este adapte os objetivos determinados pela lei nas necessidades particulares de cada classe/área.

\section{REFERÊNCIAS}

ARAÚJO, Francisco Rossal de; COIMBRA, Rodrigo. Direito do Trabalho - I. São Paulo: LTr, 2014.

BRASIL. Tribunal Regional do Trabalho da $15^{\mathrm{a}}$ Região. Dissídio Coletivo de Natureza Econômica $n^{\circ}$ 0006151-86.2013.5.15.0000. Seção de Dissídios Coletivos. Suscitante: Sindicato dos Trabalhadores nas Indústrias da Fabricação do Álcool, Etanol, Bioetanol, Biocombustivel, Químicas E Farmacêuticas de Ribeirão Preto e Região. Suscitado: Ldc Serv Biosev Bioenergia S.A. Relatora Desembargadora Adriene Sidnei de Moura David Diamantino. Campinas, 12 de fevereiro de 2014. Disponível em: <http://busca.trt15.jus.br/search?q=cache:zYGKa7vD10sJ:grumari.trt15.jus.br:1111/doc/2498 46+Diss\%C3\%ADdio+Coletivo+de+Natureza+Econ\%C3\%B4mica+n\%C2\%BA+000615186.2013.5.15.0000\&site $=$ jurisp

$\& c l i e n t=d e v \_i n d e x \& o u t p u t=x m l \_n o \_d t d \& p r o x y s t y l e s h e e t=d e v \_i n d e x \& i e=U T F-$ $8 \& 1 \mathrm{r}=$ lang_pt\&access $=\mathrm{p} \&$ oe $=\mathrm{UTF}-\overline{8}>$. Acesso em: 29 jun. 2016.

Tribunal Superior do Trabalho. Recurso de Revista $n^{\circ}$ 0000839-37.2012.5.08.0008. $3^{\text {a }}$ Turma. Recorrente: Sindicato dos Trabalhadores nas Indústrias Urbanas do Estado do Pará - STIUPA. Recorridos: Centrais Elétricas do Pará S.A. - CELPA e Outra. Relator Ministro Alberto Luiz Bresciani de Fontan Pereira. Brasília, 03 de junho de 2015. Disponível em: $<$ http://aplicacao5.tst.jus.br/consultaunificada2/inteiro

Teor.do?action=printInteiroTeor \&format $=\mathrm{html} \&$ highlight $=$ true $\&$ numeroFormatado $=\mathrm{RR} \% 20$ -

Cadernos do Programa de Pós-Graduação em Direito PPGDir./UFRGS | Edição Digital | Porto Alegre | Volume XI | Número 2 | 2016 | P. 293 - 313 


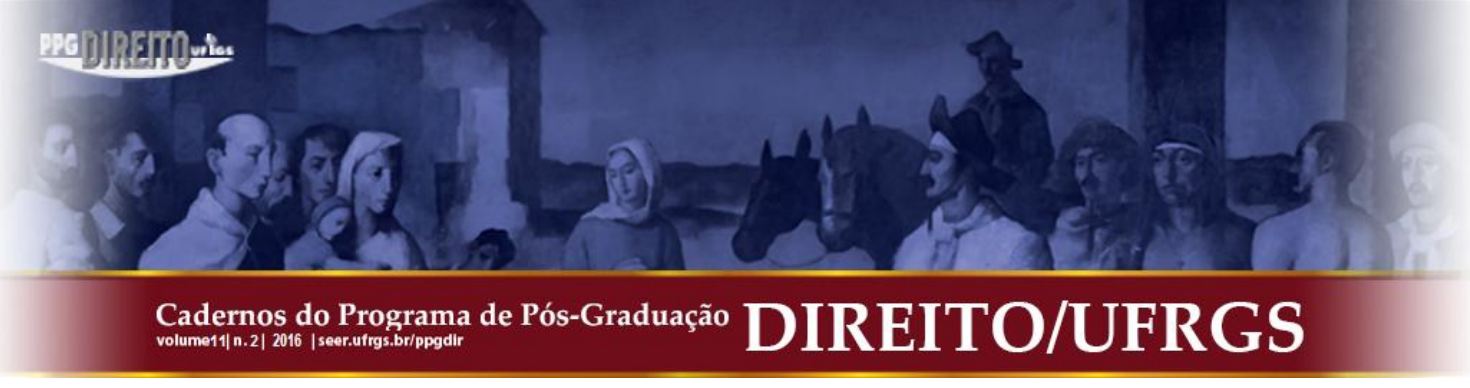

$\% 20839-37.201$

2.5.08.0008 \&base $=$ acordao $\&$ rowid $=$ AAANGhAAFAAAN61AAW $\&$ dataPublicacao $=12 / 06 / 2$

$015 \&$ localPublicacao $=$ DEJT \&query $=$ dialogo $\% 20$ and $\% 20$ das $\% 20$ and $\% 20$ fontes $>$. Acesso em: 10 jul. 2016.

CALLEGARI, André Luís; STRECK, Lenio Luiz; ROCHA, Leonel Severo (Orgs.). Constituição, sistemas sociais e hermenêutica. Anuário do Programa de Pós-Graduação em Direito da UNISINOS: mestrado e doutorado. n. 7. Porto Alegre: Livraria do Advogado, 2010 .

DELGADO, Maurício Godinho. Direito coletivo do trabalho. 4. ed. São Paulo: LTr, 2011.

DELMAS-MARTY, Mireille. Por um direito comum. Tradução de Maria Ermantina de Almeida Prado Galvão. São Paulo: Martins Fontes, 2004.

ENGELMANN, Wilson. A (re) leitura da teoria do fato jurídico à luz do "diálogo entre as fontes do direito": abrindo espaços no direito privado constitucionalizado para o ingresso de novos direitos provenientes das nanotecnologias. In: CALLEGARI, André Luís; STRECK, Lenio Luiz; ROCHA, Leonel Severo (Orgs.). Constituição, sistemas sociais e hermenêutica. Anuário do Programa de Pós-Graduação em Direito da UNISINOS: mestrado e doutorado. n. 7. Porto Alegre: Livraria do Advogado, 2010.

Crítica ao positivismo jurídico: princípios, regras e o conceito de direito. Porto Alegre: Sérgio Antônio Fabris, 2001.

Nanotechnology, law and innovation. Deutschland: LAP LAMBERT Academic Publishing GmbH \& Co. KG, 2011.

O direito frente aos desafios trazidos pelas nanotecnologias. In: STRECK, Lenio Luiz; ROCHA, Leonel Severo; ENGELMANN, Wilson (Orgs.). Constituição, sistemas sociais e hermenêutica. Anuário do programa de Pós-Graduação em Direito da UNISINOS: mestrado e doutorado. n. 10. Porto Alegre: Livraria do Advogado, 2013.

FRANÇA. Código de Trabalho. Disponível em: <https://www.legifrance.gouv.fr/affichCodeArticle.do;jsessionid=6FB218439340AB89D11E F619941A7270.tpdila19v_3?idArticle=LEGIARTI000019071126\&cidTexte=LEGITEXT000 006072050\&dateTexte=20160709>. Acesso em 09 jul. 2016. 


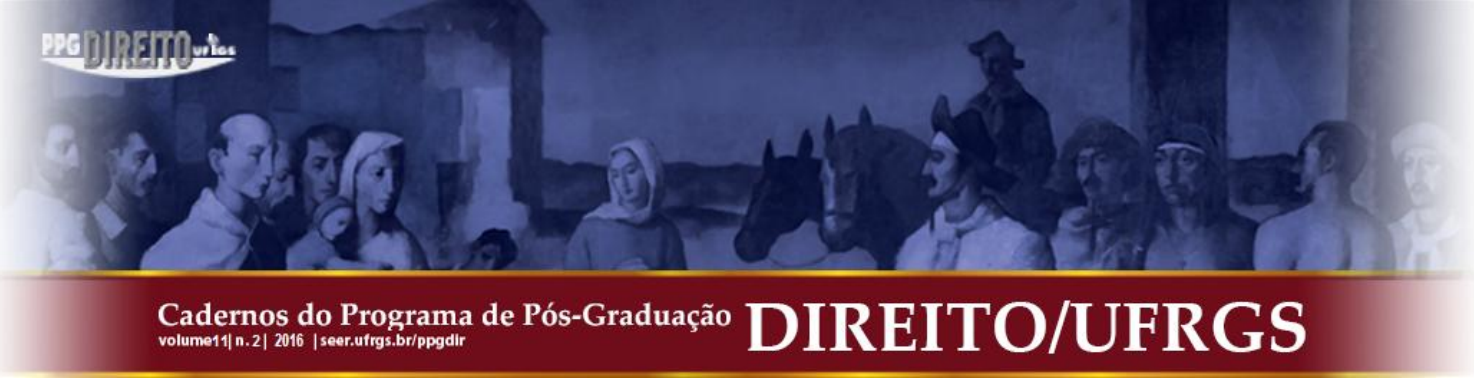

JAYME, Erik. Direito internacional privado e cultura pós-moderna. Cadernos do programa de Pós-Graduação em Direito PPGDir./UFRGS. v. 1, n. 1, mar. 2003. Disponível em: <http://seer.ufrgs.br/index.php/ppgdir/article/view/43487/27366>. Acesso em: 29 jun. 2016.

MARQUES, Claudia Lima. O "diálogo das fontes" como método da nova teoria geral do direito: um tributo a Erik Jayme. In: MARQUES, Claudia Lima (Coord.). Diálogo das fontes: do conflito à coordenação de normas do direito brasileiro. São Paulo: Revista dos Tribunais, 2012.

MARQUES, Claudia Lima (Coord.). Diálogo das fontes: do conflito à coordenação de normas do direito brasileiro. São Paulo: Revista dos Tribunais, 2012.

MELlO, Marcos Bernardes de. Teoria do fato jurídico: plano da existência. 20. ed. São Paulo: Saraiva, 2014.

MISALIDIS, Mirta Gladys Lerena Manzo de; SILVA, Lucas Gonçalves da; BARBATO, Maria Rosaria (Orgs.). (Re)Pensando o Direito: Desafios para a construção de novos paradigmas. 1. ed. Florianópolis: CONPEDI, 2014.

PONTES DE MIRANDA, Francisco Cavalcanti. Tratado de Direito Privado. Tomo I. Rio de Janeiro: Borsoi, 1954.

PORTILHO, Raphaela Magnino Rosa. O direito do trabalho na visão crítica de Alain Supiot. In: MISALIDIS, Mirta Gladys Lerena Manzo de; SILVA, Lucas Gonçalves da; BARBATO, Maria Rosaria (Orgs.). (Re)Pensando o Direito: Desafios para a construção de novos paradigmas. 1. ed. Florianópolis: CONPEDI, 2014. Disponível em: $<$ http://webcache.googleusercontent.com/search?q=cache:1XLojK2qTEJ:www.publicadireito.com.br/artigos/\%3Fcod\%3D092cb9ab3aaf99bd+\&cd=1\&hl=p tBR\&ct=clnk\&gl=br>. Acesso em: 22 abr. 2016.

SINDICATO DA INDÚSTRIA DE PRODUTOS FARMACEUTICOS NO ESTADO DE SÃO PAULO (SINDUSFARMA); SINDICATO DOS TRABALHADORES NAS INDÚSTRIAS QUÍMICAS, FARMACÊUTICAS, PLÁSTICAS, DE EXPLOSIVOS, ABRASIVOS, FERITILIZANTES E LUBRIFICANTES DE OSASCO E COTIA. Termo aditivo a convenção coletiva de trabalho. São Paulo, 19 abr. 2012. Disponível em: <http://webcache.googleusercontent.com/search?q=cache:h7RyKDTb920J: www.sindusfarma.org.br/informativos/Aditivo_Osasco2012_2013.pdf+\&cd=1\&hl=ptBR\&ct=clnk\&gl=r>. Acesso: 29 jun. 2016. 


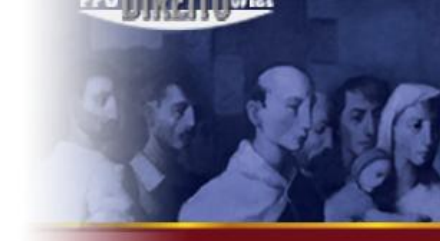

STRECK, Lenio Luiz; ROCHA, Leonel Severo; ENGELMANN, Wilson (Orgs.). Constituição, sistemas sociais e hermenêutica. Anuário do programa de Pós-Graduação em Direito da UNISINOS: mestrado e doutorado. n. 10. Porto Alegre: Livraria do Advogado, 2013.

SUPIOT, Alain. Crítica del derecho del trabajo. Traducción de José Luis Gil y Gil. España: Ministerio de Trabajo y Assuntos Sociales, 1996.

. Face à l'insoutenable: les ressources du droit de la responsabilité (Indroduction). In : SUPIOT, Alain; DELMAS-MARTY, Mireille (Orgs.). Prendre la responsabilité au sérieux. 1. ed. Paris: Dépôt legal, 2015.

Homo juridicus: ensaio sobre a função antropológica do direito. Tradução de Maria Ermantina de Almeida Prado Galvão. São Paulo: WMF Martins Fontes, 2007.

Lei e trabalho. Um mercado mundial de regras? Tradução de Rinaldo José Varussa. Tempos Históricos. v. 17, $1^{\circ}$ semestre de 2013. Disponível em: <http://erevista.unioeste.br/index.php/ temposhistoricos/article/view/9013/6604>. Acesso em 03 mai. 2016.

SUPIOT, Alain; DELMAS-MARTY, Mireille (Orgs.). Prendre la responsabilité au sérieux. 1. ed. Paris: Dépôt legal, 2015.

VENTURA, Deisy. O espírito de filadélfia - a justiça social diante do mercado total. Direito \& Práxis. v. 6, n. 12, 2015, p. 692. Disponível em: <http://www.epublicacoes.uerj.br/index.php/ revistaceaju/article/view/19320/14054>. Acesso em: 14 jul. 2016.

Submissão: 17/07/2016 Aceito para Publicação: 21/10/2016 


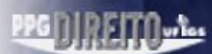

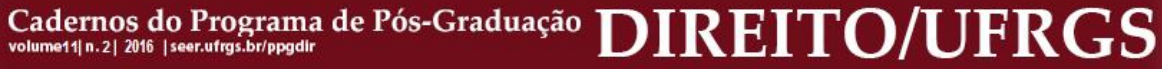

313 